Georgiana UDREA*

Diana-Luiza DUMITRIU*

Mădălina-Ștefana SCÎRLAT*

Andreea STROE*

\title{
The Role of Host-Universities in the Process of Erasmus Students' Intercultural Adaptation
}

\begin{abstract}
Within the general framework of the internationalization of higher education, this paper brings forward the role of host-universities in facilitating the intercultural adaptation of Erasmus students. In line with Kim's $(2001,2005)$ theoretical approach, the general premise that we build our research on is that the more universities involve in organizing activities which encourage communication and social relationships for the visiting students, the easier the adaptive process to the new socio-cultural medium would be for them. Based on 20 in-depth interviews with Romanian students aged between 19 and 23, who went on an Erasmus programme of 4 to 8 months in different European countries, we discuss which were the main facilitators and barriers that they had to cope with during their mobility sojourn. Although the results show a low level of host-universities engagement in facilitating the adaptive process of visiting students, we lay stress on how universities can approach this process as a win-win relation and which are the short-term and long-term implications on both individual and organizational level.
\end{abstract}

Keywords: intercultural adaptation, internationalization of higher education, academic mobility, Erasmus students.

\section{Introduction}

The academic world could not escape the wider process of globalization that generated the rise of the network society (Castells, 1996), the emergence and proliferation of global patterns of consumption, cosmopolitan lifestyles or global economic and political moves. Moreover, the academic network, as part of this phenomenon of liquid boundaries between nations and cultures, has become a key player on the global table, acting as both subject and object of this multilayered process of globalization that the entire world is coping with.

On the one hand, in terms of the globalization of the academic social field, we are facing an accelerated process of internationalization of higher education (Dervin, 2007; Pricopie, Nicolescu, Reinhardt \& Almăşan, 2009), strongly supported by the academic mobility programmes such as Erasmus. Universities understand globalization as a constitutive framework of action that increases the odds of a better compatibility between the students' professional profile as educational output and the profile of the next generation of specialists as global labour market input. Therefore, academic mobility has become more than an aim per se - it is, foremost, "a means of knowledge transfer and capacity building" (Brooks \& Waters, 2011, p.

* National University of Political Studies and Public Administration, Bucharest, Romania, contact author: georgiana.udrea@comunicare.ro. 
148), working as a significant indicator and predictor for the later labour migration (Guellec \& Cervantes, 2001).

On the other hand, there is another dimension of the globalization of the academic world, one that is rather related to the market-oriented culture that universities are embracing today under the high pressure of competitiveness. The fact that the higher education system is becoming more and more "marketized" (Geiger, 2004) makes universities act as any other organizational actor coping with such a dynamic and very competitive market. In this context, there is no wonder that a wide spectrum of university rankings are gaining both in popularity and influence (Grewal, Dearden, \& Lilien, 2008), generating a high interest and involvement in finding and applying strategic measures to remain competitive.

Covering aspects regarding institutional resources and reputational capital, these symbolic rankings have real market consequences in terms of students and investors' attraction or retention. Moreover, along with other organizational actors, universities understand that, on the long-run, the focus should be strategically moved from the tangible assets to the potential to generate knowledge, skills or know-how, and maintain a functional relationship and knowledge exchange with the socio-economic environment (Ernst, 2002).

Universities are also becoming more and more aware of their role in this triple helix development model, which brings to the fore the strong links between industry, government and the academic world (Etzkowitz \& Dzisah, 2008). In a knowledge-based economy and society as a whole, universities play an important part in building the next generations of specialists and in creating the premises for functional professional networks and transnational channels for knowledge and know-how exchanges. Therefore, universities' "responsibility to educate human talent to be able to respond to the most authentic demands of the society" (Delgado, Correa \& Cardona, 2013, p. 399) involves adapting to the needs and dynamics of a globalized market and to the high professional mobility on this market. There's no wonder that Erasmus experience can increase the entrepreneurial mindset in terms of social and professional life (Önderoglu, Sultan Oguz \& Turhan, 2010).) and, along with other academic mobility programmes, contributes to a form of brain drain (Oosterbeek \& Webbink, 2011) or, we would rather argue, to a form of circular global brain flow.

The knowledge transfer between universities and business or governmental actors provides the basis for building significant competitive advantages for the both parts involved in this exchange equation (Schofield,2013). While partnerships with universities allow companies to reduce the cost of their Research and Development investments (Perkmann, Neely \& Walsh, 2011) and to sustain the Human Resources' talent hunting process, universities themselves benefit from higher public visibility, business recognition as professional formative actor and financial support for their projects.

Moreover, this partnership is perceived to provide a more sustainable economic growth and competitive advantage (Etzkowitz, Webster, Gebhardt \& Terra, 2000) for each party involved and feed the dynamics of innovation seeking that defines the knowledge-based economy. Therefore, statements like the one that "only organizations that are part of this type of global networks are dominant and reach global recognition" (Delgado et al., 2013, p.397) seem less normative and more prospective in explaining the dynamics of market-oriented social fields.

Based on this general context of the academic world, the main aim of this paper is to address the role of universities in facilitating the intercultural adaptation process of Erasmus students. The two general assumptions that we start from regard the strategic role of academic 
mobility programmes and of students' network for the host-universities' global reputation and the win-win situation that a successful intercultural adaptation of visiting students means for both the students as individual actors, as well as for the host-universities as organizational actors. What are the major challenges that visiting students have to cope with in their intercultural adaptive process? How does the host-university involve and manage this process? How do visiting students perceive host-university's role in facilitating their intercultural adaptation process? What is at stake for the host-universities as organizational actors in providing a suitable set of measure to facilitate visiting students' intercultural adaptation?

In trying to answer these questions, we will first address the academic mobility and its adaptive challenges, together with the value of Erasmus students' network on the global labour market in order to build up a general theoretical framework for our empirical research. In the second part of the paper, we will analyze the formal communication of host-universities to visiting Erasmus students via their websites and the way Erasmus students themselves perceive the involvement of host-universities in facilitating their adaptation during the mobility period by means of in-depth interviewing. These two complementary directions will provide us with a comparative approach of the topic, having on the one side the host-university's position and, on the other side, the students' mobility experience.

\section{Academic mobility and its adaptive challenges}

Students' mobility has been considered one of the most visible indicator of the wider process of the internationalization of higher education (Pricopie et al., 2009), accelerating the globalization of both the academic and the professional world. What has been called the transnational education context and experience is strongly related to the parameters of the cultural process that students have to cope with when engaging in any academic mobility programme. Even though there is a dominant frame of addressing this intercultural adaptation in terms of home and host national cultures, as we will further discuss, we argue that there is another important dimension of this adaptive process that has received little attention in previous studies: the organizational culture adaptation.

The cultural adaptive process that students are subject to during their academic mobility sojourn should be addressed as a multilayered process, as culture involves dimensions of both national and organizational cultures (Hofstede, G., 2001; Hofstede, G., Hofstede, G.J. \& Minkov, 2010) that students are exposed to. There is also a third, more silent, dimension of occupational cultures which is rather transnational and trans-organizational and has strong structuring effects on the academic world. However, the present study will narrow its focus on some particular aspects from the two more prominent levels of adaptation. While on the national culture level, which is the core component of most academic mobility studies, we will emphasize the alternative intercultural adaptive models, on the organizational culture dimension we will discuss the host-universities' engagement and shared-interest in facilitating students' adaptation.

The common grounds of the academic mobility literature bring together the psychological approach of adaptation as individual' cognitive and behavioural response to an everchanging environment and the sociological approach of adaptation as a well-structured process which begins with the socializing and acculturation stages and ends with the identification and integration into a certain social group (Simmonet, 2009). To some extent, we can say that 
the wide spectrum of studies of academic mobility can be discussed and placed on a psychological-sociological continuит.

Although they admit the unique nature of students' adaptive process, as each mobility experience depends on a complex configuration of personal and social particularities, the literature still proposes a set of models which try to explain some general mechanisms of this adaptive process. How does it work? What toughens and what eases the adaptive process in a host-culture?

The first two theoretical models we bring into discussion follow a similar evolutional frame, identifying distinct steps which define the adaptive process. The U-Curve Model, developed by Kalvero Oberg in the 1960s, describes the emotional stages the students go through during their intercultural sojourns. Beginning with a high level of optimism, students are then facing distrust and despair when the negative aspects of the culture are revealed, experiencing what is known as culture shock. In the next stage - the acculturation stage - the individual gets more and more acquainted with the new cultural medium and he starts to accept the host culture, preparing for the calm waters of the equilibrium stage of belonging. This initial model was further developed in 1963, when Gullahorn and Gullahorn added a second curve that could also cover the process of readapting to the natural (home) culture, thus converting the " $U$ " model into a "W" one (Gullahorn, J.E. \& Gullahorn, J.T., 1963; Brein \& David, 1971).

Another model building on this multi-stage adaptation pattern is the Developmental Model of Intercultural Sensitivity advanced by J.M. Bennett (2004). It manages to make a more consistent correlation between the psycho-social experience of the adjustment process and the national culture dimension, by defining the cultural adaptation as a trajectory between ethnocentrism and ethnorelativism. Thus, starting with a negation reaction towards the new cultural model, strongly related to that of protection of the home-culture from the host one, individuals familiarize themselves with the new cultural context and tend to gradually downplay cultural differences. At this point, the adaptive process has already overcome the ethnocentrism level and the individual can begin to accept the change, getting prepared for the actual adaptation and integration stages. This, however, involves embracing mentalities and behaviours belonging to the host culture, the individual's personality being influenced by both host and home cultures (Bennett, 2004).

These models of the adaptive process are consistent with a rather general model of change management and individual reaction to chance. They are thus very similar to classical models such as Kubler-Ross's grief curve (2005) or Parker and Lewis's transition curve (1981), which have been re-contextualized so that they explain and predict organizational change dynamics and corollary individual coping strategies. Although they refer to intercultural adaptation as a specific form of change management, both the U/W-Curve Model and the Developmental Model of Intercultural Sensitivity tend to focus on the micro and the macro dimension of the adjustment process (the individual and the host national culture), losing sight of the mezzo level of the organizational culture of the host-university and its role in the adaptive process. Moreover, they propose a rather rigid approach of adaptation that seems to be very predictable, while the actual adaptive process that students may experience is more dynamic and more random, as entropy has long replaced the age of equilibrium (Bailey, 1990, p. 71).

Therefore, we turn to another model of intercultural adaptation that we consider to better fit our approach of academic mobility adaptive process, that is the Communication Systems Model developed by $\operatorname{Kim}(2001,2005)$. What this model lays emphasis on is the actual communication between the social actors involved in the general equation of intercultural adaptation. 
Analyzing items such as strangers' predispositions, hosts' communicational competence, the psychological health which stems or does not from the intercultural transformations or activities organized by the hosts, Kim concludes that the success of the intercultural adjustment is dependent on the efficiency of the communication between the parts at stake. Moreover, through long-term and cumulative communicational experiences, Kim points out that people can experience the identity changes gradually. This conceptual framework allows us to discuss hostuniversities' role and communication approach in softening visiting students intercultural adaptation, by implicitly admitting their mediator effect on the whole adaptive process.

Moreover, in line with this approach, when addressing Erasmus scholarships in Europe, Dina Strong (2011) argues that what lays ground to the adaptive process is the intercultural communication. Although it remains connected to a linear logic of the adjustment process evolution, the transition from the beginning (when students try to find compassion in the company of those experiencing the same change) to later (when they dare to extend their perspective and social network) is explained in terms of understanding the functional role of interaction and constant communication between visiting and hosting actors (Strong, 2011).

Regarding the discomfort caused by the cultural shock, Church (1982) underlines the fact that entering a totally new medium involves confrontation with a set of communicational barriers, not only verbally speaking, but also nonverbally. In this context, we argue that intercultural adaptation is not an abstract construct, but rather an interactional reality that people experience and manage mostly through communication practices. It is thus not surprising that students' general feeling of comfort, which is perceived to be defining for the success of the adaptive process, comes along with proficiency in a foreign language, high level of self-esteem, self-trust, positivism, social relationships and stress reduction (Kamal \& Maruyama, 1990; Matsumoto, Wallbott \& Scherer, 1989).

Furthermore, the countries' multicultural ideology is a factor bound to influence greatly the adaptive process. Berry calls attention to the fact that while certain countries implement programmes to facilitate the foreigners' integration, others try to segregate them from their domestics (Berry, 1997, p. 167). In the case of the Erasmus scholarships, some universities offer guest students special rooms in their campuses, which only makes the symbolic distance between students be preserved, along with the cultural distance between the home and the host context. Inevitably, this hardens the adaptive process if not really stops it (Zapf, 1991). In the same light, the fact that the courses are being taught in English makes it even more difficult for the students to truly adapt socio-culturally to the host culture (Strong, 2011), also contributing to an imbalance in international mobility in terms of language of instruction (Pricopie et al., 2009, p.105).

However, besides students' interest and need for adaptation to their host-culture, what is at stake for universities? Why should universities involve in facilitating visiting students' adjustment process? Are the adaptive measures taken by universities only functionally-oriented or do they cover strategic aspects as well?

In order to address these aspects the entire adaptive process needs to be transposed into the market-oriented logic of universities as organizational actors. In terms of organizational management, adapted and integrated visiting students mean higher level of satisfaction and motivation which, in turn, become significant predictors for academic performance in general (Hunley, 2010), and mostly for the engaged students. Going further, this is the most sustainable process of gaining them over and converting them into long-term brand ambassadors for the university in both academic and industry fields. Visiting students are a valuable cap- 
ital for any university on the global market, as they may become strategic nodes of communication in a global professional network. The short-term objective of facilitating their adaptation can hence be integrated into a long-term objective directed towards a strategic reputational management.

Moreover, the success of an academic mobility sojourn, which is highly dependent on the success of students' adaptive process, can consolidate the inter-universities collaboration, generating new opportunities for common projects and flows of knowledge exchange. The reputation of a good host-university for academic mobility programmes is a strong competitive advantage not only for attracting the elite students and academic organizational partners, but also for research funds and transnational research projects. All these aspects contribute to the internationalization process that universities are subject to and to their better positioning as a "professional pool of talents" and as a trusting partner for the major business actors (on their dual role as employers and potential investors).

Universities themselves act as academic multinational organizations, which means that diversity management and intercultural communication have become strategic already. That is why facilitating students' adaptation to the national and organizational host-culture needs to be addressed as a win-win situation for both students and universities. Moreover, universities have their own organizational culture that raises new adaptive challenges for students in terms of identity, identification and rules of action. However, the normative framework imposed by international mobility programmes such as Erasmus have acted towards increasing the similarity between universities, regardless of their national culture dimension, thus working as a globalizing force within the academic world.

Pressed by the status they feel they have to assume in their host environment (Tsoukalas as cited in Brooks \& Waters, 2011), students enter an organizational medium that should help them solve and overcome the dysfunctional culture shock stage. Even though "all individuals possess a capacity of thinking something and doing anything else" (Linton, 1964), thus providing superficial and rather imitative behavioural practices for coping with a new sociocultural context, genuine adaptation requires a two-side approach from both visiting students and host-actors.

The adjustment to the host culture, especially in the first stage of students' mobility sojourn, is strongly related to the manner in which the students interact with what can be called the functional proximity context (that is the academic experience they are faced with in their dominant role as visiting students). Moreover, Levinger and Raush (as cited in Peng, 2011) argue that friendship, which has a positive influence on the intercultural adaptation, is subject to the following five elements: frequent interaction, spatial proximity, the existence of common goals, sharing the intimate and caring for each other, all of which, in turn, can be facilitated by the organizational measures taken by the host-university. Thus, from accommodation aspects and bureaucratic procedures, to curricula and social network issues, the hostuniversity can play an important role in toughening or easing the students' adaptive process.

Universities benefit from academic mobility programmes at least as much as individual students do and, therefore, the intercultural adaptation of visiting students should be addressed from both actors' perspective and corollary interests. Students' mobility is part of a wider phenomenon of professional elite globalization and becomes a significant component in building and reshaping the long-term transnational network between the academic and the business professional fields. Thus, facilitating students' adjustment process can become a winning card on the long-run in terms of both reputational and financial capital for the host-universities as organizational actors who aim to remain competitive on the global educational market. 


\section{Methodology}

The methodology we have chosen in this paper is qualitative. It resonates with Daly's (2007) call for future studies examining the processes of intercultural sojourn by considering more detailed qualitative analysis of in-country experiences, in order to gain a deeper understanding of the time abroad and how it may cause changes within the individual. Along the same line, some authors argue that "a more sophisticated analysis of the personal, social and academic experiences that students undergo during their mobility can be achieved only by indepth interviewing of international students" (King \& Ruiz-Gelices, 2003, p. 247).

Also, qualitative studies on Erasmus students' sojourning experience (the focus of this work) are scarce in general, and especially when it comes to students from the newer EU Member States, such as Romania. We have interviewed 20 Romanian students aged between 19 and 23, who have pursued an Erasmus stage of 4 to 8 months in different European countries. They were chosen randomly from reliable lists of returned Erasmus students originating from the NUPSPA, The University of Bucharest, or The Economic Studies Academy, and asked to participate in a research on the foreign students' experiences abroad.

The interviews, which lasted, on average, about 30 minutes each, were face-to-face interactions and were conducted in Bucharest over the course of 3 months (December 2013- February 2014). Furthermore, they were designed to look informal and free, in spite of a quite precise interview guide. They were semi-structured, ensuring that specific themes were addressed, but also allowing enough flexibility so that other pertinent information may emerge. The main research questions that guided the analysis referred to a) the major challenges that visiting students have to cope with in their intercultural adaptive process, b) the involvement of host-universities in managing this process, c) the way visiting students perceive host-university's role in facilitating their intercultural adaptation process and d) identifying what is at stake for the host-universities as organizational actors in providing a suitable set of measure to facilitate guest students' intercultural adaptation.

Students' participation in this research was voluntarily, and the respondents were not offered any financial or other incentives. To determine them to be open and honest, they were told that the interview was totally anonymous and strictly designed for academic use.

\section{Findings and discussion}

\subsection{The pre-mobility phase of the intercultural adaptive process}

The adaptive process that the visiting students are subject to is prefaced by an important phase that they go through before leaving their home-country. There are two important components that this pre-mobility phase brings to the fore: on the one hand there is a consistent process of information assimilation about the host-university and country/city they will go to and, on the other hand, there is the emotional preparation for this experience.

Looking back to this moment and evaluating it from the perspective of their entire mobility experience, only 9 of the 20 students said they were well-informed before leaving the country: "I talked with a person who dealt exclusively with international students... I was able to find accommodation and whatever materials I needed that semester" (C., 23 y/o., Netherlands). Moreover, it should be noted that the students were rather informed about the 
Erasmus formalities which had to be followed and about the host-university they have chosen to join and less about the host country and culture. We can thus speak about a functional approach as dominant in this pre-mobility phase of the intercultural adaptive process. The procedural and formal aspects are the ones that students focus on, being less social and more task-oriented in preparing their academic sojourn.

However, this orientation does not only reflect students' positioning to the mobility experience they will go through, but also a conjunctural informational reality regarding the level of accessibility, the amount and the nature of the data they find about the academic sojourn in their host-culture (on both organizational and national dimensions). The pre-mobility phase is, yet, very important for the adaptive process, because it sets students' expectations regarding their mobility experience and, moreover, the information they leave with about the host-university and national culture can facilitate their adaptation and reduce the impact of a new cultural context. We would thus argue that if visiting students would manage the pre-mobility phase effectively and universities would involve more in helping them in this matter, the emotional intensity of the cultural shock phase and its duration could be considerably reduced.

\subsection{Managing the cultural shock phase of intercultural adaptation}

As we have already discussed in the first part of this paper, the beginning of the mobility sojourn is very challenging in terms of emotional intensity. This was also confirmed by all the students that we have interviewed, as for many of them it continues to be a referential moment in defining the mobility experience as a whole. However, some students identified an interesting aspect, as they admitted that the need to deal with all the difficulties of this first phase of the mobility sojourn kept them busy enough and, to some extent, took their minds of the emotional struggle of adapting to a new place and culture.

Another consistent aspect that almost every Erasmus student referred to in speaking about the beginning of the mobility sojourn was the limited network of students that they reached to: "My first day there was a little risky because it will always be like that when you go someplace new. I interacted mostly with those I had gone with there, with the three colleagues from Romania that I ended up staying in the apartment with and then we managed to acquaint ourselves with the other college groups" (S., $20 \mathrm{y} / \mathrm{o}$, Spain). Trying to find understanding and comfort, students usually turn to those that go through similar experiences, thus to other visiting students. Moreover, there seems to be a prioritization logic based on cultural similarity. Thus, visiting students first look for students from their home-country, laying the basis of a micro-national community that helps students confront the unfamiliar rules about how life should be lived in the new cultural environments.

This favours the formation of what the literature calls "enclaves of students of the same nationality" (Church, 1982, etc.) and the organizational solutions for the incoming students' accommodation encourage this phenomenon. Having a distinct part of the university campus prepared for the visiting-students, the host-universities create symbolic territorial boundaries between guest and local students. Therefore, it comes as no surprise that almost half of all the students we have interviewed said they have mostly interacted with their co-nationals (with whom they started the "Erasmus adventure" or whom they just met there), the host students and locals remaining mostly distant and difficult to socialize with. The cultural and emotional closeness to other visiting students and, moreover, to those coming from the same country as them, is also enforced by this spatial proximity that the host-universities provide 
thorough this symbolic accommodation territoriality. Sharing the same space favours direct interaction and social experiences sharing among the guest students and this consolidates what is known as the Erasmus students network.

When speaking about friendship bonds, which play a key-role in the overall adaptive process, almost all the surveyed students remembered the friendships they had tied up with other foreign students whom they spent the most time with. The empathic basis of their relationship, as they shared the same status and challenges as visiting students, became even more prominent when the host-universities applied this logic of symbolic segregation in setting down the accommodation territories within the campus. However, what many theoreticians critic as real enclaves, act as ad-hoc communities that built up the Erasmus students' global network. Therefore, as one student notices, the atmosphere in those foster homes near the international accommodation zone in the campus is special: "The unit where we lived was crammed only with foreign students... we would do stuff together ... we would all cook together ... it was super. Oh! and the building where we sat had been a container and, so, we named ourselves the container family" (C., $23 \mathrm{y} / \mathrm{o}$, Netherlands). This last metaphor is very expressive, as it puts together the emotional intensity of the guest-students' identification with the Erasmus community as an ad-hoc family. Moreover, it adds a more salient component of inferiority in respect to the (self) representation of the visiting students in comparison to the other students (see the use of ,container" analogy).

The explanations provided by this lack of interaction with the people from outside the visiting-students group were quite varied; they ranged from those who blamed the locals for being too distant and less willing to interact with foreigners (i.e. "they are not the warmest people ... the French will be French..." - M., 20 y/o, France) or from those invoking local stereotypes and prejudices towards the Romanians, in particular, to those indirectly admitting their part of blame (i.e. "I think one of my greatest regrets is that I failed to make more Dutch friends" - C., $23 \mathrm{y} / \mathrm{o}$, Netherlands) or explicitly admitting that it was their choice to spend most of their time with other Romanians (part of whom they have already known before leaving the home-country, i.e. friends or classmates). Similar to the results put forward by other studies on the topic, this last explanation seems to reveal that one of the most powerful means of adjustment abroad for the Romanian Erasmus students remains their increased interaction and friendship with co-nationals. In this regard, as it was previously mentioned, because of the anxieties associated with immersing themselves in the host culture, many Romanians tended to form enclaves of fellow nationals. On the one hand, establishing these primarygroup relations allowed students to maintain familiar, traditional values and belief systems; on the other hand, these enclaves served as "reference groups" with whom the new environment could be interpreted, discussed, compared and often criticized. However, despite the benefits their interaction with co-nationals has brought along, most of the Romanian respondents admitted that their contact with the local or the international students and people was restricted in this way.

In brief, this in-group orientation of Erasmus students' social life during their academic sojourn, which is even more intense in its first period, has a functional value on the short run, as it reduces the anxiety and impact of the cultural shock phase. The in-group orientation is clearly based on the advantages of empathy, which means that the academic community of Erasmus students has a significant emotional component. However, on the long run, focusing on the community of the foreign students makes the adaptation process to the host national culture more difficult, reducing the interaction with the locals. 


\subsection{Host-universities' webpage as tool in facilitating the}

\section{adaptive process of visiting-students}

While analyzing the qualitative data from our interviews with Romanian Erasmus students, we decided to add another dimension to our research and to explore the universities' own position towards the academic mobility programmes and the guest students' adaptive process. Therefore, we have chosen to bring into discussion a formal component of the hostuniversities' communication, i.e. the way they address the mobility issue on their official websites. In this sense, we covered 13 sites of the host-universities that the 20 interviewed Romanian Erasmus students have attended in different cultures (e.g. Spain, Portugal, Italy, France, Slovakia, Latvia, Lithuania, Belgium). The general premise was that, being the most important public communication channel that the universities turn to for both informing about and promoting their activities and academic offers, the decision regarding what, where and how to cover on the official website can reveal the universities' positioning towards and the importance they give to a certain issue. Moreover, as we discussed in the previous sections, during the pre-mobility phase of the intercultural adaptive process and the first phase of the academic sojourn, the students are involved in an important process of finding and assimilating relevant information about the host-university, town and national culture. In this process they mostly rely on official information provided by the host-university.

Having this in mind, we looked over the websites of all the host-universities that our research subjects have attended as Erasmus visiting students, with the main objective of identifying how universities address the academic mobility issue. The aspects that we emphasized while analyzing this secondary corpus of website content were related on the one hand to the importance given to the academic mobility component within the universities' public agenda (as it can be reconfigured based on the websites' list of topics) and, on the other hand, to the type of information and measures that the host-universities are focusing their formal communication on.

When speaking about the importance given to aspects regarding the academic mobility, we used as indicators: the availability level of information (How hard it is to find this information on the university site?), the autonomy level of information (Is this information given distinct section/s on the websites? Are these sections in the main tab bar or are they rather secondary tabs?), and the level of language hindering (Is there a language impediment in receiving the information?). We believe that the way the universities approach these aspects reflect their positioning towards the academic mobility programmes and their involvement in setting the proper grounds for a successful integration of the visiting students. Moreover, they can facilitate or harden/ roughen the visiting students' adaptation, giving that the fact information is the sine qua non condition of any adaptive process.

A first aspect that we have noticed is that most universities have a distinct section dedicated to the international component of their activity. Whether they choose a more general formula such as "International"/ "International cooperation"/ "Mobility" or more specific ones, addressing mobility programmes themselves "Erasmus students"/ "Erasmus", the universities seem to have understood the need to address these publics with more targeted information. Most of the sections are part of the main bar of tabs or they are subordinated to sections like "For students", which confirms the strategic role of this component for the overall dynamics of the organization. Moreover, to widen their addressability, most of the information on the universities official sites, especially within the international activity-related section, is available in other international languages (except the national one). However, it's 
easy noticing the dominance of the English versions, informally acting as the world-wide language of the academic network, contextually followed by French, Spanish and German. This comes to confirm a serious imbalance of the language of instruction (Pricopie et al., 2009, p. 105) in favour of English.

If we were to consider these formal aspects regarding the accessibility of the information, we can say that it is no far than two-three clicks distance after one entered the home-page of the universities' websites. Also, if one is an English speaker, one should have no problem in getting informed about the host-university and its academic sojourn as visiting student. Nevertheless, the problems begin when addressing the content component of these sections and the actual way of organizing this information.

The host-universities seem to focus on the administrative process of the visiting students' adaptation, that is on providing functional information regarding accommodation, cost of living, financial support or internship opportunities, official documents needed for enrolment or the general legal framework for the mobility programme (including the list of Erasmus partners, Erasmus Standard University Charter, etc.), contact persons/ departments for academic mobility programmes. Along with this type of information, the universities also cover sub-sections regarding the academic programmes/ offers and the language courses aimed to facilitate the guest students' intercultural adaptation. However, all these aspects, which the universities emphasize through the sections addressed to the international students, are rather related to a short-term functional adaptation to the host-universities and less to the national (host) culture as adaptation referent. They are mainly intended to answering to questions about how the visiting students can perform better as part of their new organizational context rather than as part of the host national context.

When it comes to aspects regarding the social component of the student life in the new culture, the information is more difficult to find (if there). However, there can be found some aspects concerning students associations, the campus life or the life in the host-city, leaving the national culture dimension on a secondary place/ in the background. Understanding the importance of the adaptive process and the challenges that the guest students have to cope with during their academic sojourn, some universities have provided several guiding steps comprised in various sections such as: "Guide for incoming students", "Incoming Student Information Package", "Campus life"; or, more frequent, they have offered sections with information regarding the cultural and associative opportunities, practical recommendations for every-day life (i.e. A few steps not to miss when you arrive in Lyon) or other useful links. Yet, the information is rarely well organized and easy to find and it mostly has a high level of generality.

The last aspect that we wanted to address in presenting this exploratory analysis of the hostuniversities websites refers to those sections that bring to the fore the organizational level of visiting students' intercultural adaptation. In this respect, we can find information like that provided in the following brochures: "Seven great reasons for studying in Passau"/ "Live the UOC"/ "Welcome to UFC brochure", which moves the focus on the host-university and secondary on the host-national culture, linking the university branding with the host-city branding.

\subsection{Organizational actors and their involvement in facilitating students' adaptation}

Another dimension that we focused on in our analysis related to identifying how the hostuniversities choose to involve in facilitating students adaptive process. We thus looked for whether and what kind of actions they take in this regard. The very interesting fact was that, 
when addressing the issue regarding the events organized in order for the Erasmus students to integrate easier abroad, most of the subjects recalled the informal activities prepared by the student organizations. It seems that among them, the Erasmus Student Network (ESN) Organization was the most active one. As one of the biggest worldwide student associations, ESN aims to provide opportunities for cultural understanding and self-development under the principle of "Students Helping Students", providing social and cultural events as a general framework for interaction between students and being rather orientated towards informal activities. However, despite its global dimension and declared interest in helping international students adapt themselves to the host-culture they have chosen to study in, as most students noticed, ESN is more focused on helping the Erasmus students get along with each other than on helping them interact and understand more about the host-culture and the local community.

Back to the actual involvement of the host-universities, only 4 out of the 20 Erasmus respondents remembered events exclusively organized by the universities. The common aspects defining these events reflect their formal nature and their time-frame, as most of them have been planned in the first period of the visiting-students' academic stage: "The first day we had a reception or... something like a dinner, they gathered us all [...] to get to know the teachers and ask as many questions as necessary" (J., $20 \mathrm{y} / \mathrm{o}$, Spain). Thus, it can be said that, the main role of these events was to keep to the ceremonial constrains of the academic communication contract that the mobility programmers have generated over time. Moreover, they provide students with the opportunity to meet their teachers, to get familiar with the organizational environment they will become part of, and to acting more or less as a symbolic moment of being accepted into the host-university community.

The other common aspect that the students underlined regarding the host-university's involvement in facilitating their adjustment refers to the language courses provided for the visiting students, in order to help them interact more easily with the locals and reduce the language barriers of the overall adaptive process. Given the fact that they usually cover the two or three weeks before the actual begging of the university year, some students find these language courses not very efficient for their day to day life in the host-culture, as "you have no chance of actually having a decent conversation after only three weeks of the course" (H., $22 \mathrm{y} / \mathrm{o}$, Belgium). Still, they have rather become a standard action that is taken in most academic mobility programmers, and reaffirms the important role that the language proficiency plays in the intercultural adaptation process.

The two aspects that we find highly important in addressing the activities organized by the universities for the visiting-students' well being and temporary adaptation are: the curve of the organizational efforts, which is very unbalanced (with most of the activities planned at the beginning of the academic sojourn), and, secondly, the other unbalanced relation between the host-universities' involvement and the student organizations' implication in managing the Erasmus students' foreign adjustment.

\subsection{How effective were host-universities' measures in facilitating students' adaptation?}

Taking all these a step forward, we were interested in students' positioning regarding the effectiveness of the events discussed above. Did they find them useful or not? Based on their sojourning experience, what are the most important factors that contributed to their adaptive process and what would they recommend to be done by the host-universities to improve their involvement in this process? 
Evaluating their whole mobility experience, only 5 out of the 20 Erasmus interviewees admitted that the extra-curricular activities they participated in during their academic stage had a significant role in their adaptation. One of the reasons for this low efficacy of such activities was related by some students to the lack of interactivity in the formal events organized by the host-universities: "I do not feel that it helped me much, I got so tired... the last part was just about speeches and presentations on the history of the country" (R., $20 \mathrm{y} / \mathrm{o}$, Slovakia). This type of evaluative position puts forward not only the limits of the very formal events, but also the visiting students' expectations and need for increased communication situations that would encourage the interaction among participants, thus moving the focus from the informational content, to the social and relational one.

Another argument for the poor impact of the host-universities' actions directed towards the visiting-students was related to the internal factors involved in the adaptation process. Thus, the students' own capabilities in coping with the host-culture and the corollary adaptation challenges were considered to be defining for the entire mobility experience: "they did not necessarily help my process of adaptation, but I think that it depends a lot on you if you adapt or not ..." (M., 20 y/o, France).

When considering the activities addressed to the visiting students, there can be observed a consistent orientation towards event-related activities with a low academic profile. Generally speaking, students tended to remember parties and trips, presentations of the countries of origin, concerts, sport events and theatre performances as the main activities they took part in. This, along with the public cause of global students' organizations like ESN, may explain why the Erasmus educational sojourn is increasingly perceived as a cultural and social phenomenon (King \& Ruiz-Gelices, 2003; Sigalas, 2010), being less defined in academic terms and rather understood as an intercultural experience of European mobility within the general public sphere.

Among the most important aspects that the visiting students had to cope with in adapting to the new context were the elements related to the national cultural distance (i.e. "People are very quiet and serious. The thing that caught my attention was the fact that on the bus no one is talking [...] which is very different from Romania... they do not make eye contact... they say it is not polite... or something. [...] I say it's weird..." - L., $20 \mathrm{y} / \mathrm{o}$, Latvia), the organizational cultural distance (i.e. "I felt the difference between the two education frameworks. I mean, there were 4 course weeks and then the exams. Imagine that! It was extremely difficult to get used to that" - C., $23 \mathrm{y} / \mathrm{o}$, Netherlands), the language barrier (i.e. "I knew some Portuguese, put as it was not my mother-language that meant that it was very hard for me to be myself... hmm ... and this prevented me from showing who I really was" - M., $23 \mathrm{y} / \mathrm{o}$, Portugal) and even those inconveniences related to the climate change or to the "home-sick syndrome" that most of the students experience during their mobility sojourn.

Asked about the most common factors that helped students surpass both the academic and the socio-cultural obstacles while abroad, there were some adaptive elements that topped our respondents' lists. Among them, we mention the events organized by ESN, their friendship with other international students, the teachers' empathy and the micro-communities of students that provided them with the emotional and practical support they so much needed. All these aspects leave the actual organizational effort of the host-university outside the most highlighted means of adjustment in students' view, and reaffirm the low involvement and efficiency of their activities (as we consider that students' relation with the teachers is rather build on an individual level and not on an organizational one). Thus, the prominence of the 
aspects related to the in-group activities of the Erasmus students in particular or to the visiting-students in general (from other mobility programmes too), together with the limited timeframe of the mobility sojourn converge can make the intercultural adaptation of Erasmus students harder. Thus, we argue that, in many cases we can rather speak about a functional short-term intercultural adaptation, which depends more on the individual adaptive capacities than on the ad-hoc measures taken by the host-universities.

\section{Conclusions}

Beyond the specific observations and mobility experiences that our study tried to relate to the theoretical debate on Erasmus students' intercultural adaptive process, we argue that the main contribution of this article is to have laid stress on the organizational level of the visiting-students' adjustment to the host-cultures. Most studies addressing the intercultural adaptation of students during their academic sojourn have focused on their individual psychosocial experience and on the way they manage the cultural differences between their home and their host culture. However, they tend to ignore or minimize the role of the host-universities as organizational actors in this adaptive process and the impact that their actions can have in facilitating it. Therefore, while revealing the functional implication of the host-universities' actions in softening the visiting-students' adaptation to a new culture, we also provided consistent arguments in attesting the strategic value of these actions for the university reputation.

The interest in taking part in educational mobility programmes such as Erasmus has become a constitutive component of the wider internationalization process of the academic world - especially when it comes to the higher education, which is closer related to the professional world. As the universities' websites show, this international dimension of their activity acts as defining for the university and, moreover, responds to their more and more prominent market-orientation. And what can be more persuasive then this formal international recognition that one of the partners in an academic mobility network built up through these programmes? Universities play the international card as legitimizing tools and prestige sources not only for convincing international students to come and study there, but also for finding other institutional partners for their projects, investments and funding for their research. It also can be a great argument and competitive advantage in convincing local students to choose them over other universities in the region.

What is interesting in that during the ceremonial public events organized for the guest students and also on their official websites' communication, universities seem to adopt a rather superficial approach in this matter. They mainly keep their discourse in a very old-fashioned and generic register, with little evidence of creativity and differentiation in exploiting the marketable value of this internationalization component. It seems that the important thing is to "mark of" this internationalization standard, without a real and deeper involvement in constantly and consistently managing it.

As both the interviews and the exploratory analysis of the host-universities' sites have shown, communicating with the visiting-students has a dominant functional nature, the universities focusing more on the procedural and practical aspects of their academic sojourn and less on the social and cultural dimension of their experience. Besides this inefficiency of the host-universities' actions in facilitating their adaptive process, the students also pinpointed to the imbalanced timeframe of the universities' involvement, stressing an overloading of events and formal communication situations in the first weeks of the academic sojourn. 
Moreover, it seems that not only do universities share their host-role with students organizations (such as the ESN), but, to some extent, we can even speak of a silent "externalization" of the responsibilities of the socio-cultural events and psychological support for the visiting students to these organizational actors. Given their sustained involvement in the informal activities and to their focus on making the mobility experience as pleasant as possible, there is no wonder that students tend to speak more about the extra-curricular activities than about the academic life, about the host-city and the other guest students than about the host-university and its local students. Indirectly, this contributes to the public perception of the educational mobility programmes as less academic and more recreational and of the Erasmus students as rather travellers than students.

Another important aspect that our analysis puts emphasis on is that not only do host-universities take few real measures and actions to support visiting-students' adaptive process, but they actually add more challenges to it. The most consistent observation that the students made during the interviews was related to the side-effect of the accommodation conditions they provided to the foreign students, i.e. bringing them together in separate units of the campus. Through this symbolic segregation, the universities encourage and sustain the formation of micro-communities of incoming students, strengthening the in-group relations and the identification with these communities that are built up on similarity and empathy. Even though the host-universities rely mostly on students' organizations (such as the ESN) for maintaining the communication with the visiting students and helping them to adapt to the new culture proves to be problematic. This happens because these organizations focus on activities that involve only or mostly the international students, hence, acting especially towards consolidating their micro-community and less towards providing them with increased opportunities to interact with locals.

The real challenges the students had to cope with during their academic sojourn, and, more importantly, the superficial level of getting to know, understand and adapt to the host-environment can be related to these communication problems that the host-universities didn't succeed to manage. Thus, it confirms Kim's $(2001,2005)$ approach of the intercultural adaptation as strongly dependent on the efficiency of the communication between the parts, in our case the visiting students and the host-universities.

Building on the general observation that the Romanian Erasmus students made when addressing the efficacy of the host-university's actions and the factors that impacted and facilitated their adaptive process, we would argue that universities should re-evaluate their role in this process and focus more on providing constant and consistent opportunities for interaction between the locals (students, teachers, community representatives etc.) and the visiting students. Moreover, they should direct their attention not only to the content of their communication relation with the guest students, but also to the way it is presented, structured and delivered. It is not enough for the host-university to communicate with the visiting students in order to facilitate their adjustment process, it is far most important what, how, and when they communicate.

Finally we argue that the host-universities should be more aware of the market value that the international students' network has on the long run and should also understand that they need to strategically approach the communication relation with them. This, in turn, will facilitate not only students' intercultural adaptation to the national host-culture, but, more important, it will ease their adaptation and identification with the university organizational culture, creating the proper premise for their role as global ambassadors for the university 
brand. In terms of methodological approach of the intercultural adaptation issues, we think that the current studies should focus more on this organizational level and on the role of the host-universities within the whole adaptive process. Moreover, the exploratory analysis of universities' websites can be a very resourceful direction to follow, as developing and applying a more systematic analysis guide will allow interesting comparative considerations.

\section{References}

Bailey, K. (1990). Social Entropy Theory. Albany, New York: State University of New York Press.

Bennett, M. J. (2004). Becoming interculturally competent. In J.Wurzel (Ed.) Toward multiculturalism: A reader in multicultural education, (pp.62-77). Newton, MA: Intercultural Resource Corporation.

Berry, J. W. (1997). Immigration, acculturation, and adaptation. Applied psychology. 46(1), 5-34.

Brein, M., \& David, K. H. (1971). Intercultural communication and the adjustment of the Sojourner. Psychological Bulletin. 76(3), 215-230.

Brooks, R., \& Waters, J. (2011). Student mobilities, migration and the internationalization of higher education. Basingstoke: Palgrave Macmillan.

Castells, M. (1996). The Rise of the Network Society. Oxford: Blackwell.

Daly, A. (2007). Outbound Student Exchange at Australian and New Zealand Universities: the Effects of Pre-Departure Decision-Making, In-Country Experiences and Post-Sojourn Outcomes. Retrieved August 15, 2013 from: http://www4.gu.edu.au:8080/adt-root/public/adtQGU20090219.145337/index. html.

Delgado, H. C., Correa, Z., \& Cardona, Y.A. (2013). The role of a public university in a global environment: networks and externalities of the R\&D of the Cauca University. Estudios Gerenciales. 29, 396-405.

Dervin, F. (2007). The Erasmus experience: halcyon days of hypermodernity. Retrieved June 25, 2014 from http://users.utu.fi/freder/general.pdf

Ernst, K. (2002). COH Muttart research Project. Hull outcome monitoring and evaluation system: COI outcome model. Canadian Outcomes Institute, Retrieved May 5, 2014 from: http://www.hmrp.net/CanadianOutcomesInstitute/projects/pdf_common/HOMESOutcomeModel.pdf

Etzkowitz, H., \& Dzisah, J. (2008). Rethinking development: Circulation in the triple helix. Technology Analysis \& Strategic Management. 20(6), 653-666.

Etzkowitz, H., Webster, A., Gebhardt, C., \& Terra, B.R.C. (2000). The future of the university and the university of the future: Evolution of ivory tower to entrepreneurial paradigm. Research Policy. 29, 313330.

Geiger, R. (2004). Market Coordination In Higher Education: the United States. In P. Teixeira, B. Jongbloed, D. Dill, \& A. Amaral (Eds.), Markets in higher education: Rhetoric or reality? (pp. 161-184). Dordrecht: Kluwer.

Grewal, R.; Dearden, J.A., \&. Lilien, G.L.(2008). The University Rankings Game: Modeling the Competition among Universities for Ranking . The American Statistician, 62(3), 232-237.

Guellec, D., \& Cervantes, M. (2001), International Mobility of Highly Skilled Workers: From Statistical Analysis to Policy Formulation, International Mobility of the Highly Skilled.. In OECD Proceedings: International Mobility of the Highly Skilled, Retrieved May 29, 2014: http://pesona.mmu.edu.my/ chtan /Seminar/9202011E.pdf

Gullahorn, J.E., \& Gullahorn, J.T. (1966). American students abroad: professional versus personal development. The Annals. 368, 43-59.

Hofstede, G. (2001). Culture's Consequences: Comparing Values, Behaviors, Institutions and Organizations Across Nations (2nd ed.). Thousand Oaks, CA: Sage.

Hofstede, G.; Hofstede, G.J., \& Minkov, M. (2010). Cultures and Organizations: Software of the Mind (3rd ed.). New York: McGraw-Hill. 
Hunley, H. A. (2010). Students' functioning while studying abroad: The impact of psychological distress and loneliness. International Journal of Intercultural Relations. 34(4), 386-392.

Kamal, A.A., \& Maruyama, G.(1990). Cross-cultural contact and attitudes of Qatari students in the United States. International Journal of Intercultural Relations. 14, 123-134.

Kim, Y. Y. (2001). Becoming Intercultural: An Integrative Theory of Communication and Cross-Cultural Adaptation. Thousand Oaks, CA: Sage.

Kim, Y.Y. (2005). Inquiry in intercultural and development communication. Journal of Communication. 55(3), 554-577.

King, R., \& Ruiz-Gelices, E. (2003). International Student Migration and the European 'Year Abroad'. Effects on European Identity and Subsequent Migration Bihaviour. International Journal of Population Geography. 9, 229-252.

Kübler- Ross, E. (2005).On Grief and Grieving: Finding the Meaning of Grief Through the Five Stages of Loss. New York: Scribner.

Linton, R. (1964). The study of man. New York: Applection Century-Crofts.

Matsumoto, D., Wallbott, H. G., \& Scherer, K. R. (1998). Emotion and intercultural communication. Handbook of Applied Linguistics. 7, 15-38.

Oosterbeek, H., \& Webbink, D. (2011). Does Studying Abroad Induce a Brain Drain?, Economica. 78 (310): 347-366.

Önderoglu, S., Sultan Oguz, E., Turhan, B. (2010). Developing an entrepreneur mindset through Erasmus. International Journal of Euro-Mediterranean Studies. 3 (1), 103-112.

Parker, C., \& Lewis, R. (1981). Beyond the Peter Principle - Managing Successful Transitions. Journal of European Industrial Training. 5 (6), 17-21.

Peng, F. (2011). Intercultural friendship development between Finnish and international students. Master Thesis, Retrieved May 15, 2014: https://jyx.jyu.fi/dspace/bitstream/handle/123456789/27287/URN\%3ANBN \%3Afi\%3Ajyu-2011071211147.pdf?sequence=1

Perkmann, M., Neely, A., \& Walsh, K., (2011). How should firms evaluate success in university-industry alliances: A performance measurement system. R\&D Management. 41(2), 202-216.

Pricopie, R.; Nicolescu, L.; Reinhardt, Z., \& Almășan, O. (2009). Dynamics in the Internationalization of Higher Education at the Global Level and Specific Trends in Romania. Romanian Journal of Communication and Public Relations. 11(3), 103-110.

Schofiel, T. (2013).Critical Success Factors for Knowledge Transfer Collaborations between University and Industry. The Journal of Research Administration. (44)2, 38-57.

Sigalas, E. (2010). Cross-border Mobility and European Identity: The Effectiveness of Intergroup Contact During the Erasmus Year Abroad. European Union Politics. 11(2), 241-265.

Simonet, G. (2009). Le concept d'adaptation: polysémie interdisciplinaire et implication pour les changements climatiques. Natures Sciences Sociétés. 17(4), 392-401.

Strong, D. (2011). Discourse of Bi-national Exchange Students: Constructing Dual Identification. In F.Dervin (Ed.) Analysing the consequences of academic mobility and migration. Newcastle: Cambridge Scholars Publishing.

Zapf, M. K. (1991). Cross-cultural transitions and wellness: Dealing with culture shock. International journal for the advancement of counselling. 14(2), 105-119. 